elastic ether hypothesis which satisfied us in Maxwell's days, we should carry on with no change in our methods.

Silvanus Thompson, in his inaugural presidential address on the founding of our society, referred to the youthfulness of that branch of engineering which we practise. It recalled, he said, illuminations on the proclamation of peace after the Crimean War. "Bengal lights and rockets. How the vision of them stands out in memory! But our society has as little to do with fireworks as with fireflies. As little-and as muchfor, after all, both of them are assuredly of some interest to the illuminating engineer."

He knew that the secret of the firefly is still hidden from us, but that if we knew it, if we knew how to produce the rapid vibrations which give the stimulus called light, without producing all the slow ones as well, as when we sound a high note with a finger instead of pressing all the keyboard at once, the mechanical equivalent of light would be as important as the mechanical equivalent of heat, and we should be able to produce light without heat. The quantity of energy which appears as useful light is about 2 per cent. of the energy radiated from an electric glow-lamp; in the firefly it is about 96 or 97 per cent. In other words, if we could produce a highly efficient lamp, the lightgenerating output of a dynamo would be fifty times greater than now, and $45 \mathrm{lb}$. of coal would do what a ton does to-day. The cost of lighting will not be reduced in anything like the same proportion. The cost of fuel is about one-tenth of the selling price of the light. The ordinary London householder pays $3 d$. to $6 d$. for his domestic lighting, which entailed a consumption of about $0.44 d$. of coal at pre-war prices.

While so many engineers and scientific men have been eager to do something for the war, and so few have succeeded in linding any appreciation of their services, our society must be content to have been allowed to carry out more than one investigation for which it was well fitted. Silvanus Thompson said that fireworks, as well as fireflies, were of some interest to the illuminating engineer. The star-shell, flares, and parachute lights which play so important a part in the war are but fireworks. The chemist has used his skill to choose the most suitable compositions, and ingenuity has been expended in putting them up and in priming them; but in estimating the results, no further progress had been made beyond the stage of Lambert-the eye alone was the judge. Fortunately the right men in the right department were approached. It was recognised that photometric tests would be useful. Our society offered to find men who would suggest methods and give their time, if necessary, to carry out the work. A committee was accordingly formed; it conferred with the experts, who cordially placed their data and requirements before the members; a special photometer was at once discussed, designed, and made. At the present time nothing more can be said than that the instrument has fulfilled all expectations; it needs no manipulation whatever during observations, measurements may be taken over large ranges, and the behaviour of unsteady or flickering lights can be recorded. The observations on a large number of samples, both of service patterns and of experimental kinds, were made by the committee during night meetings, and were reduced to candle-power-seconds per gram of composition, and it is hoped that the results have been useful.

Some five and twenty years ago it seemed likely that luminous paint would have many useful applications, but the results were disappointing. The preparation of one of the best kinds was kept secret, and it was never properly placed on the market. Night operations of No. 25I9, VOL: IOO] war have directed attention to this subject, and the old method of exciting zinc sulphide or other materials by light has given place to continuous stimulation by $\alpha$ rays of radium compounds. Dials of watches and compasses are well known, and luminous gun-sights are no secret, but there are other applications which cannot be described at present. On these a committee of our members has been working. Tiny tubes are used which are smaller and give less light than a glowworm, but in their preparation careful photometric measurements of considerable difficulty have been made and valuable information has resulted from the research.

More work is wanted, or at all events more accessible literature is needed, on the physiology of vision. The dioptrics of the eye are well understood; its normal, abnormal, and pathological characteristics are the basis of ophthalmic science. The theory of colour vision is still, perhaps, unsettled, though no one worker will admit it. The subject to which I wish to refer is a purely quantitative one, and is the relation of light flux to visual perception. The range of the luminous stimulus to which the eye can respond is enormous. When we grope our way on so dark a night that objects are only just visible, the illumination is about one-tenthousandth of a foot-candle, or equal to that received from a candle at a distance of $\mathrm{Ioo} \mathrm{ft}$. In summer sunshine we often have 5000 foot-candles, and in clearer atmospheres than ours 10,00o foot-candles are reached. The brightness of a furnace is even higher, and furnacemen judge the temperature by the colour.

By some marvellous organic control the eye so reacts that it is capable of estimating difference of tone and colour over a range of several thousand millions. The contraction of the pupil has very little to do with this regulation. It merely seems to take advantage of a greater stimulation to reduce spherical aberration. Over a large part of the enormous range Fechner's relation between stimulus difference and sensation difference holds good. There must be some intricate and delicate provision, perhaps, of a chemical change in the receptive portion of the eye, the retina, depending on saturation or exhaustion of material; or some inhibition of the transmissive portion, the optic nerve, or some compensatory reaction or opposing activity or fatigue in what Huxley called the sensificatory portion, the brain. The automatic adjustment of control which permits so sensitive an organ to accommodate itself to such great changes in the external stimulus has its counterpart in other organs and functional mechanisms of the body, such as those which are concerned in breathing. If physiologists could tell us something about this quantitative control, it would help us in several ways.

\section{SCIENCE AND THE COLD-STORAGE}

$$
\text { INDUSTRY.1 }
$$

THE value of perishable produce imported into this country, subject more or less to refrigeration, was, before the war, about $130,000,000 l$. per annum. It is abundantly evident that the most natural means of preserving foodstuffs, $v^{*} z$. by methods of low temperatures, have gained the confidence of our merchants, and the cold-storage industry to-day is a striking example of the successful combination of soience, commerce, and industry. The history of the cold-storage movement reveals four outstanding features:-

(I) It is difficult to imagine a more striking example than the cold-storage industry affords of the success of the spirit of enterprise and love of adventure which have always characterised British commerce.

1 From a paper read before the Royal Society of Arts on December rg, rgin, by Prof. J. Wemyss Anderson. 
(2) Refrigerating engineers have been in no sense less typical, inasmuch as the methods employed are scientifically sound, the machines of the leading manufacturers are thoroughly trustworthy, and the necessary low temperatures for the transport and storage of food have been made a sound commercial proposition.

(3) Refrigeration has played a most important part in the development of some of our Colonies-particularly Australia and New Zealand.

(4) While the applied science of the engineer has done much for the advance of cold storage, pure science has in this country done little or nothing for the commercial preservation of foodstuffs.

The principal foodstuffs at present cold-stored can be roughly divided into three classes:-

(I) Produce the life-history of which is finished, such as all classes of meats. poultry, rabbits, and fish.

(2) Produce the life-history of which is not finished, such as fruit and eggs.

(3) Milk and produce from milk-cream, butter, and cheese.

It has been found that with good rearing of sound stock, combined with scientific methods of slaughter, and a thorough system of veterinary inspection and hygienic after-care, beef can be kept in the chilled (soft or unfrozen) state for five or six weeks. This time permits of a voyage from North or South America, together with the time necessary for collecting the cargo at one end and its distribution at the other-in this country. This time allowance cuts out all possibilities of a chilled beef trade with Australia or New Zealand with low temperatures only.

Then, with all classes of meats, poultry, and rabbits, certain troubles manifest themselves from time to time - such as mould. Often the troubles are epidemic and caused by ignorance or carelessness prior to shipping, while often only a small percentage of an overseas consignment is affected and the source of trouble cannot be found by the trader.

Fish has been preserved in many ways, but it is safe to say that refrigeration is destined to outrival, in bulk, all other methods. Research work is urgently needed in this direction, both with respect to meeting periods of glut and for general preservation and transport. The main questions to be determined are :-

(I) What kinds of fish will stand preservation the best?

(2) What are good methods, and, if possible, the best with each kind of fish?

(3) Which seasons of the year are the best adapted for each form of preservation?

(4) What are the food values and general effect for each method of preservation on the principal kinds of fish?

When the best methods have been determined, there still remains the problem of educating the public taste. In the British Isles the problem is mainly how to get the fish to the markets in a fresh state. Coldstorage methods will help this, but wider researches are required for the fishermen who go far to sea, and also for fish imported in a frozen state from our Colonies.

The preservation of both fruit and eggs, if properly understood, would mean a great saving of wealth to the country, and also better health. It seems very doubtful if new-laid eggs will ever again be sold in any part of the country at $6 d$. a dozen. With respect to fruit, refrigeration has enabled this country to enjoy a perpetual autumn; but the methods that enable Australian fruit to be eaten in a sound condition in this country are not applied to home-grown fruit. Why? The fruit merchants of this country have had to depend on the pure science of countries No. 25 I9, VOL. IOO] other than our own to help them to keep material the life-history of which is not finished. Fruit and vegetables offer an immense field for research.

Milk and its products open up a still greater field. Sterilisation as usually adopted hopelessly destroys its structure, and, no doubt, correspondingly destroys its food value. Common-sense deductions point to mechanical milking into covered vessels, the whole to be cooled down to $3^{\circ}$ or $4^{\circ} \mathrm{C}$. as soon as possible after the milking operation, and then kept away from the air until the time of consumption. Milk so treated and kept cold will keep quite sound, with ordinary commercial handling, for more than a week-theoretically, it should last for months.

The main questions may now well be asked: What has stood in the way of scientific development in the past, and what are the suggestions for the future?

With respect to low-temperature work, the answer to the first question can be readily divided into two main reasons:-

(r) The want of a bond or link between pure science and industry.

The present time is most opportune, and if the man of science will only realise that laboratory results are not by any means conclusive, he will find the man of commerce will help him in researches of a practical nature; the net result will be more commerce and a higher and better scientific knowledge.

(2) The man of science has not had facilities in his laboratory for low-temperature work. Many researches stop short at the melting point of ice or a little below.

Every seat of scientific learning should have a refrigerating apparatus as part of its equipment. No research of any kind where temperature is a function can be considered complete that does not go down to the lowest limit reasonably attainable, yet how many institutions are there where such investigations are possible? The lack of such facilities, in the light of recent advances all over the world, will constitute a serious disadvantage to our men of science, and the question must be taken up by every scientific body in the kingdom.

The author suggests :-

(I) That institutes of research and schools of refrigeration should be instituted in London and Liverpool. (This suggestion has been approved by the Cold Storage and Ice Association.) These institutes would be attached to learned institutions, and would act as centres for research work and the higher instruction of graduates (or others duly qualified) in medicine, science, engineering, and veterinary science from home and Colonial universities. They would also keep definitely in touch with Government departments and associations interested in low-temperature work.

(2) That every seat of scientific learning should provide facilities for low-temperature study and research.

(3) That every engineering school of university rank should provide facilities for refrigerating engineering study and mechanical research.

(4) That the principal technical colleges and schools under the Board of Education should be provided with facilities for instruction in mechanical refrigeration.

\section{UNIVERSITY AND EDUCATIONAL} INTELLIGENCE.

OXFORD. - The first election to a biological scholarship under the bequest of the late Mr. Christopher Welch, of Wadham College, will take place in July next. The scholarship is of the annual value of rool., and is tenable for four years. Candidates must be undergraduate members of the University; they may offer either botany, animal physiology, or zoology, and 